\title{
Analyzing Different Approaches to the Relations with the Insurance Intermediaries on the Non-Life Insurance Market in Bulgaria
}

\author{
$\mathrm{PhD}$ candidate Desislava Lyubomirova Racheva \\ University of Economics - Varna, Varna, Bulgaria \\ desislava_racheva@ue-varna.bg
}

\begin{abstract}
The non-life insurance market in Bulgaria is relatively unified when ot comes to terms of conditions and rates. This makes establishing a competitive advantage for insurance companies a difficult, multifaceted and complex task. The desire to achive leading market positions, in line with the development of a stable policy in terms of risk exposure dictates the need to systematically analyze the actions of market participants - competitors, customers, intermediaries. This article will summarize some of the approaches for studying the relationships in the channels for the realization of the insurance service and will propose a complex one in which to unite the positive aspects of each of them and to neutralize the negative ones.
\end{abstract}

Keywords: insurance intermediation, non-life insurance market, sales channel, insurance service, competitive advantages, buyer power

JEL Code: G22, M31 DOI: https://doi.org/10.36997/IJUSV-ESS/2020.9.3.117

\section{Въведение}

В литературата остават неизяснени и недостатъчно засегнати въпросите за изследване на конкурентоспособността на застрахователните дружества и как тя се влияе от ефективността и състоянието на каналите за реализация на застрахователната услуга. Що се отнася до такива изследвания в българската икономическа литература те почти неприсъстват. Ако ги има, то те са насочени към преплитане на финансовите интерпретации с маркетингови концепции, без да се изследват взаимоотношенията при предлагането на застрахователните услуги, динамиката в нормативните регулаторни рамки, конфликтите и конфликтните точки и източните на сила при преговорите между участващите страни. Регулярните статистически обобщения, предоставяни от Комисията за финансов надзор, без задълбочен анализ и пречупване през собствената статистическа информация на конкретната застрахователна компания, не са достатъчни при изграждането на стратегия за развитие на дружеството.

Изследването на една комплексна взаимовръзка, каквато представлява тази между застрахователните компании и застрахователни посредници на общозастрахователния пазар, е предизвикателство. Не сьществува достатъчно ясен и доказал се с времето приложим подход за изследване на това взаимодействие. Застрахователните компании по-скоро по случаен и неструктуриран начин изграждат своята стратегия и оперативна дейност във връзка със застрахователните посредници. Ограничават се с разглеждането на този канал за реализация на застрахователната услуга приоритетно от юридическа гледана точка - като едно договорно взаимоотношение или като обект на дейността на специализирани структурни звена на застрахователната компания тип „Брокерски бизнес“ или като обем реализиран премиен приход или като разход, съпьтстващ дейността на застрахователната компания заради изплатените комисионни възнаграждения.

Всеки от тези подходи за разглеждане на взаимоотношенията в канала за реализация на застрахователната услуга има положителни страни, очертава даден аспект от тази съвместна работа, осигурява методи за нейното изследване и подсказва посоки за нейното управление. Въпреки това, недостатъчно пълно характеризира комплексността на това взаимодействие. Настоящият доклад има за цел да систематизира някои от подходите за разглеждане на връзката „застрахователна компания - застрахователен посредник“, да опише техните предимства и недостатъци и да предложи насока за тяхната интеграция и развитие, 
за да са в максимална степен адекватни и приложими в практиката.

Полученият като резултат подход може да се използва като отправна точна и инструмент на застрахователните компании да анализират и управляват взаимоотношенията със застрахователните посредници на общозастрахователния пазар в България.

\section{1. Едностранни подходи за разглеждане на връзката „застрахователна компания - застрахователни посредници“"}

Подход към взаимоотношението „застрахователна компания - застрахователен посредник“ от юридическа гледна точка

Акцентът тук се поставя приоритетно на разглеждането на тази връзка като договорно взаимоотношение. Разбира се, този факт е неуспорим и безприкословен. Всяко взаимоотношение „застрахователна компания - застрахователен посредник“ започва с нейното юридическо създаване и официализиране чрез подписването на договор. В зависимост от типа на посредничество това са договор за застрахователно агентство, договор за застрахователна услуга по чл. 295 от Кодекса за застраховането или договор за застрахователно посредничество. Независимо от вида на договора в него се описват предметът на това взаимоотношение, правилата, по които ще се извършва, правата и задълженията, които се пораждат, както и начините за неговото прекратяване.

Основните части на това договорно взаимоотношение са:

Предмет на договора;

Права и задължения на посредника;

Права и задължения на Застрахователя;

Специфични права и задължения по отношение на работата с информационните системи на застрахователя; политиката във връзка с личните данни; политики във връзка с конфиденциалността;

Възнаграждение и начин на плащане;

Допълнителни условия;

Приложимо право;

Приложения;

Декларации, изисквани по закон.

Положителните аспекти на подхода към взаимовръзката „застрахователна компания - застрахователен посредник“ от юридическа гледна точка са:

- Задължителният характер за съществуването на взаимовръзката в правното пространство;

- Очертаване на основните параметри на тази взаимовръзка;

- Конкретната структура предполага, че еднотипни договори могат да се приложат за всички посредници от конкретен вид (застраховател агент, застрахователен брокер, посредниците, предлагащи застрахователни продукти като допълнителна дейност)

- $\quad$ Еднаквостта на договорите ги прави лесни за администриране;

- Съгласуваността им с европейските норми и директиви ги прави приложими и за чуждестранни посредници, които искат да развиват дейност на българския общозастрахователен пазар.

- Създават възможността за управление на взаимовръзката по отношение на срокове, размер на комисионните възнаграждения и задължения;

- $\quad$ Предоставя възможност бързо да се имплементират промени в законодателната рамка на страната чрез анексиране на договорите;

Предоставя изходната информация, която се предоставя на държавния надзорен орган в лицето на Комисията за финансов надзор за броя и вида на застрахователните посредници(поднадзорни лица) - данни за сключените договор

Недостатыци на този подход са: 
Изключително ограниченият поглед върху сложната взаимовръзка - само от юридическа гледна точка - спазване на нормативните и регулаторни изисквания към тази дейност;

- Липсват параметри, които да помагат за анализ на дейността на посредника и за изграждане на стратегия за управление на тази врьзка;

- $\quad$ Липса на обвързаност с постигнатите резултати на посредника;

От гореописаното следва да се заключи, че разглеждането на взаимодействието „застрахователна компания - застрахователен посредник“ само чрез този подход е задължителен, но абсолютно недостатъчен за изграждане на стратегия за управление на тази взаимовръзка. Той е само основата, която дава възможността за изграждане на взаимоотношенията със застрахователните посредници.

Подход към взаимоотношението „застрахователна компания - застрахователен посредник“ от гледна точка на организационната структура на застрахователната компания и изграждането на специализирани структурни звена тип „Брокерски бизнес"

Дейността на съвременните застрахователни компании, действащи на общозастрахователния пазар в България, макар и неподчинени на системни изследвания, а по-скоро отговарящи на изискванията на самия пазар, налага създаването на специализирани звена, част от тяхната вътрешно-фирмена структура, които да са „лицето“ на компанията към застрахователните посредници.

В техния ресор е ежедневната комуникация с посредниците по отношение на промени в общите, специалните и тарифните условия на застрахователната компания, макетите на застрахователните договори и предложения, начина и формите на отчитане и др. Те изготвят досиетата на застрахователните посредници и създава база данни с информация за клоновата структура на конкретния посредник (адресите и контактите на офисите му), точни данни за неговите служители, които имат достьп до информационните системи на компанията и т.н. Следят и за регистрацията в срок на посредническите договори пред Комисията за финансов надзор. Обработват публикуваната информация за дейността на застрахователните брокери на общозастрахователния пазар и я сравняват със справките от вътрешната информационна система на компанията. Изготвят анализи за дейността на посредниците по отношение реализирания премият приход за конкретен период.

Положителните страни на този подход са:

- Създаването на специализирано звено, в което работят специалисти, които имат за основна задача да поддържат връзката със застрахователните посредници;

Поддържане на актуална база данни с всички служители на посредниците и техните контакти, като по този начин се създава нов и леснодостьпен канал, по който може да се предава информация на посредниците;

Възможност да се поставят конкретни задачи на това звено - анализ на статистически данни, търсене на обратна връзка след проведена кампания; проучване на мнението на посредниците и др.

\section{Недостатъци са:}

Усложняване на вътрешно - фирмената структура на застрахователното дружество - необходимостта да се свърже звено „Брокерски бизнес“ с всички останали отдели на компанията, по начин, по който да позволява то да изпълнява функциите си - да е част от всички промени, инициирани от продуктовите дирекции, да е в постоянна връзка с правна дирекция, да осъществява координация с териториалните структури (агенции и представителства), да докладва пред управителните органи на застрахователната компания;

Изготвянето на анализи е основно на база публикувани данни от Комисията за финансов надзор за реализирания от застрахователните брокери премийния приход за 
конкретен период от време (шестмесечие или на годишна база).

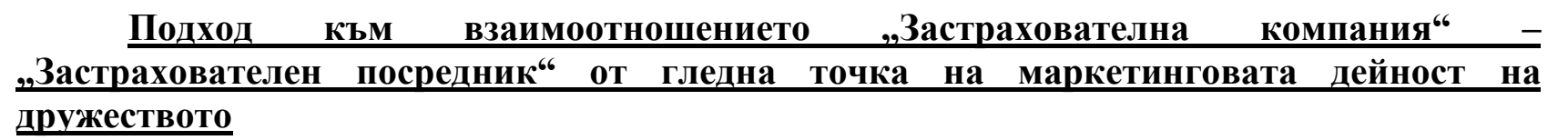

Развитието на застрахователния пазар налага необходимостта от целенасочена и специфична маркетингова дейност в по отношение взаимоотношенията със застрахователните посредници. „Стремежът на застрахователите към увеличаване на застрахователния портфейл, към разширяване сферата на застрахователната дейност и към разпростиране на застрахователния бизнес извън пределите на националния застрахователен пазар не би могло да бъде успешно без подходяща маркетингова политика.“ (Misheva, 2016).

Чрез комуникационната си политика застрахователната компания се стреми да предаде послание, което да има потенциала да въздейства върху целевите клиенти, по начина, по който компанията цели - по отношение на изграждане на имидж или затвърждаване на такъв; по отношение стимулиране на застрахователно търсене; провокиране на интерес към нови застрахователни продукти; създаване на усещане на стабилност и сигурност и т.н. Създаването на желание в потребителите на застрахователни услуги да получат информация за нов застрахователен продукт индиректно влияе върху връзката „застрахователна компания - застрахователен посредник“ като прехвърлят инициативата към посредниците. Те, под натиска на клиентите, сами ще изискват да обогатят връзката си с компанията по отношение на информация, финансови параметри при предлагането на този нов продукт (комисионно възнаграждение, допълнителни стимули и др.), рекламни материали, необходимост от обучение и др.

Важен елемент от комуникационната политика на застрахователната компания е и така наречената „обратна връзка“, представляваща информация за реакциите на целевите клиенти и участниците на застрахователния пазар към компанията. Поради по-гъстата си клонова мрежа с много точки за продажби и увеличаващата се роля на застрахователните посредници, те се явяват точният начин за набирането на тази обратна информация.

Друг елемент от маркетинг микса на компанията, в който участват застрахователните посредници е пласментната политика, която може да се определи като „комплекс от мероприятия на застрахователното дружество, насочени към реалното потребление на застрахователните услуги и продукти“ (Misheva, 2016). Връзката „застрахователна компания - застрахователен посредник“ по отношение на пласментната политика се разширява и освен основната си функция по сключване на застрахователния договор на място между застрахователя, действащ чрез своя посредник и клиента. Допълнителните функции, които изпълняват посредниците са по отношение на следпродажбено обслужване - обслужване при промени в застрахователните параметри, събиране на разсрочени вноски, помощ при завеждане на щета, следене за изтичане на застрахователния договор и др. Разнообразната дейност на застрахователните посредници е и една от причините все повече клиенти да предпочитат сключването на застрахователни договори именно чрез посредничеството на застрахователни посредници. От друга страна, работата с местни застрахователни посредници би позволило на нова за конкретния пазар компания адекватно да се позиционира с минимум разходи по проучване.

\section{Положителен аспект:}

- Разглеждане на връзката в няколко аспекта - от комуникационна гледна точка и от пласментна гледна точка;

Обогатяване на връзката със съдържание - добавяне на възможността за протичане на информация и от страната на посредниците към компанията;

Възможност за прилагане на известни и вече използвани маркетингови стратегии, без да е необходимо съставянето им за първи път сега; 


\section{Присъщи за подхода ограничения са:}

От маркетингова гледна точка на връзката „застрахователна компания застрахователен посредник“ се гледа еднопосочно - от компанията към посредника, без да се акцентира достатъчно и на обратните потоци на информация и действие.

- $\quad$ Маркетинговите похвати следва да се приведат в съответствие със спецификата на застрахователната услуга;

- Маркетинговата дейност не дава възможност за изследване на финансовите резултати от предприетите мерки;

Липса на показатели, които еднозначно да докажат, че конкретното състояние на връзката „застрахователна компания застрахователен посредник“ е в резултат от проведената маркетингова стратегия;

Подход към взаимоотношението „Застрахователна компания" „Застрахователен посредник“ от гледна точка на оперативния контролинг във връзка с дейността на застрахователните посредници

Част от тази дейност обхваща анализ на текущите парични потоци. Получената информация е в посока на реализирания премиен приход за конкретен период от време. Тези данни осигуряват възможност на застрахователната компания да следи входящите парични потоци и да ги структурира в зависимост от различните канали за реализация на застрахователната услуга. (виж Фиг.1).

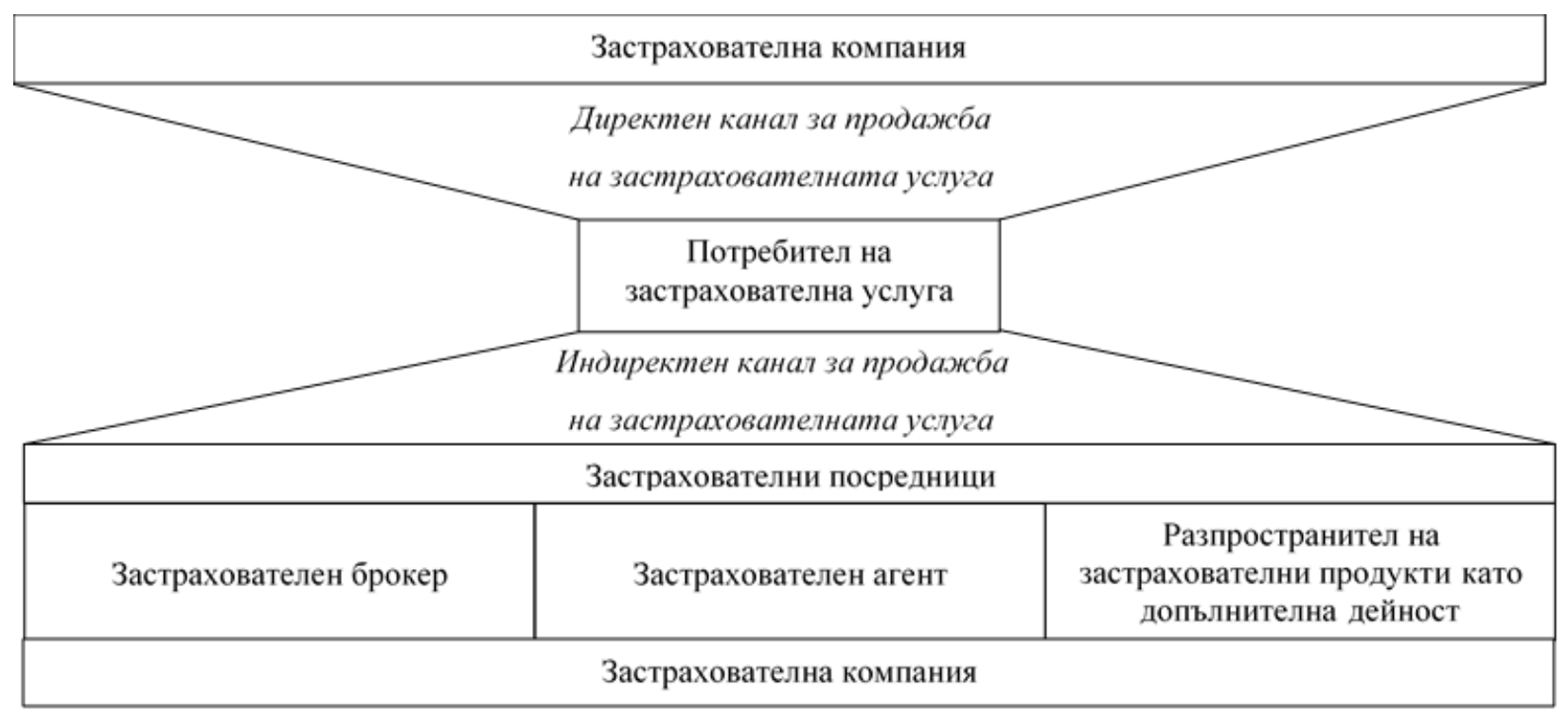

Фигура 1. Канали за реализация на застрахователна услуга.

Въпреки че този подход към връзката „застрахователна компания - застрахователен посредник“ дава отговор на въпроса какъв процент от приходите са реализирани от дейността на застрахователните брокери, агенти и посредник, предлагащ застрахователни продукти като допълнителна дейност, той е само статичен израз на взаимодействието между страните. За да се изследва динамиката на тези парични потоци, тяхното влияние от конкретни фактори и действие и на двете страни се изисква задълбочен анализ, който не се извършва от финансовите структури на застрахователните компании. Информацията за генерирания премиен приход от посредниците за определен период от време се използва и за база за изчисление на дължимите комисионни възнаграждения (предварително определен процент от акумулираните премии по всеки вид застраховка), които застрахователните компании следва да изплатят. 
За погледа на връзката „Застрахователна компания - застрахователен посредник“ от финансова гледна точка положителните страни са:

Осигурява измерим критерий на взаимовръзката - реализиран премиен приход за определен период от време и изплатено комисионно възнаграждение за определен период от време;

- Лесна и бързо достьпна информация от счетоводните разчети на компанията;

- Подава сигнали за състоянието на връзката с посредниците;

- $\quad$ Предоставя възможност за лесно вземане на оперативно решение от страна на управляващите дружеството;

- Разширява схващането на взаимовръзката - потоците в нея протичат двустранно и следва да се анализират както входящите потоци, така и изходящите такива;

- Необходима основа за анализи на дейността на дружеството;

Негативни страни:

- Взаимовръзката се разглежда само в плоскостта на финансово-счетоводната отчетност, най-често, в рамките на една финансова година;

- $\quad$ Не показва динамиката в развитието на отношенията с посредниците;

- $\quad$ Води се автономно и не отчита измененията на застрахователния пазар;

- $\quad$ За финансово-счетоводната отчетност е достатьчно да се получи крайния размер на премийния приход, без да се прави портфейлен анализ на дейността на посредниците.

От всичко гореописано следва да се заключи, че:

1) Използването само на един или приоритетно на един от подходите носи в себе си присъщите му недостатьци и непълноти и няма потенциала да разкрие пълнотата на взаимовръзката „застрахователна компания - застрахователен посредник“;

2) Продажбата на застрахователни продукти е част от общата търговска дейност в страната в сферата на търговията с услуги и на нея може да се погледне и чрез приоми, повече присьщи за анализа на тьрговската дейност;

3) На изследваното взаимодействие между участниците на застрахователния пазар не следва да се гледа на чисто договорно взаимоотношение, пораждащо юридическа обвързаност и размяна на парични средства;

4) На взаимовръзката трябва да се погледне и от позиция на конкурентно предимство и да се изследва чрез адекватни за това методи;

5) Развитието на връзката „застрахователна компания - застрахователен посредник“ има потенциал да се превърне в трудно за имитиране конкурентно предимство, което да промени изцяло пазарната позиция на застрахователната компания;

6) Системното изследване, управлението и оптимизацията на потоците в тази връзка следва да е приоритетен ангажимент на мениджмънта на всяка застрахователна компания, която иска стабилно и успешно да развива.

Това са причините, които налагат изграждането на един нов подход за разглеждането и изследването на връзката „застрахователна компания - застрахователни посредници“.

2. Разширен и комплексен подход за разглеждането и изследването на връзката „застрахователна компания - застрахователни посредници“.

Първа насока е разширяване и допълване на схващането за протичащите потоци във връзката както е показано на фигура 2.

Финансовите потоци към застрахователната компания са основно под формата на акумулирани застрахователни премии; събрани вноски към гаранционен и обезпечителен фонд и събран данък по силата на закона за данъка върху застрахователните премии в сила от 01.01.2011 г. Задължително за по-пълното изследване на връзката с посредниците е изготвяне на портфейлен анализ за дейността на посредника по застрахователни продукти и 
сьпоставянето му с този на компанията от една страна, от друга - с този на дейността на посредника като цяло, и от трета страна - с този на пазара.

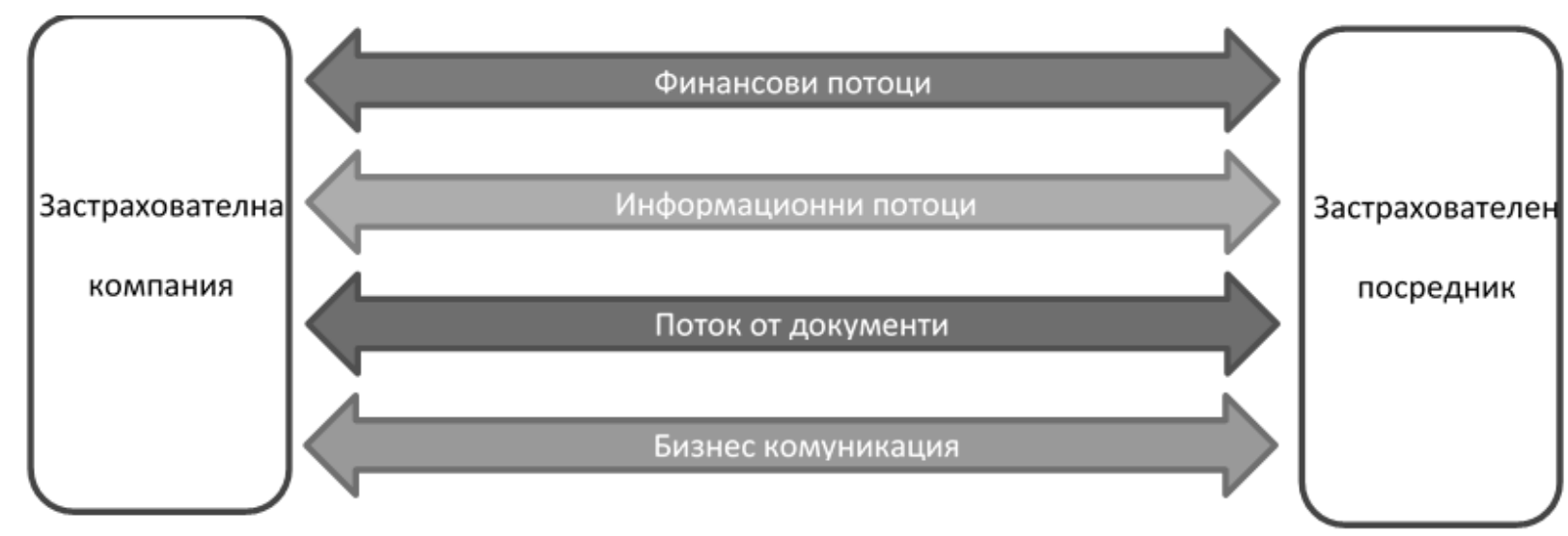

Фигура 2. Състав на потоците, съставящи връзката „застрахователна компания застрахователен посредник“

По посока от застрахователната компанията към посредника най-вече се превеждат комисионни възнаграждения. Полученият от посредника комисион в процент и абсолютна сума също следва да се групира по видове застрахователни продукти. Размерът на това възнаграждение следва да се съпостави със средните на пазара, данни за които се публикуват от Комисията за финансов надзор. На тази информация следва да се гледа и като на един от лостовете за контрол и въздействие.

Информационните потоции са с изключително разнообразно съдържание. От една страна това е двустранната комуникация по отношение на основните продукти, които се предлагат от застрахователната компания, а от друга - размяна на конкретни параметри по искане за застрахователна оферта.

В този втори случай контактна страна от името на застрахователната компания е обслужващото за посредника териториално звено - офис, представителство, агенция.

Потокът от документи представлява всички електронни и хартиени документи, които страните си разменят - рекламни документи, информационни документи, общи и специални условия, предложения, оферти, застрахователни договори и полици, отчети, фактури и мн. др.

Бизнес комуникацията - изключително богат спектьр от предаване на насрещни послания, характеризиращи исканията на двете страни. От просто, текущо предаване на оперативна информация, тази комуникация често се превръща в основа за водене на преговори, породени от конфликтните интереси на страните. Такива например са описаните по-долу:

1) Желанието на застрахователните компании да увеличат реализирания премиен приход и печалбата си срещу желанието на застрахователните посредници за увеличаване на тяхното комисионно възнаграждение;

2) Желанието на посредниците да сключат застрахователен договор и да получат комисионно възнаграждение без значение рисковата експозиция на клиента си срещу нежеланието от страна на застрахователните компания да приемат в съвкупността си високо рискови клиенти;

3) Желанието на застрахователните посредници да помогнат и обезпечат клиента си със застрахователно обезщетение (дори и когато такова не му се полага изцяло или в пълен размер), за да си осигурят силна връзка с клиента и подновяване на застрахователните договори срещу нежеланието на застрахователните компании неоснователно да изплащат застрахователни обезщетения; 
4) Желание от страна на посредниците да прехвърлят по-голяма част от етапите (офериране и изготвяне на полици) по сключване на застрахователен договор към компаниите, за да намалят необходимостта служителите им детайлно да се запознават с всички застрахователни продукти срещу желанието на компаниите да прехвърлят част от етапите (офериране и изготвяне на полици) по сключване на застрахователен договор към посредниците, за да могат да съсредоточат действията на служителите на компанията към мониторинг, контрол и обучение;

5) Желанието на застрахователните посредници да сключат застрахователна полица бързо и лесно, без задълбочаване в рисковите параметри, защото при равни други условия, по-бързото сключване на полица предполага по-голям брой сключени застраховки като цяло и по-голям размер на комисионно възнаграждение срещу желанието на компаниите да съберат достатъчно пълна информация, за да могат правилно да определят рисковата експозиция и правилно да калкулират застрахователната премия;

6) Желанието на посредниците да наемат нископлатени служители само с основни знания в сферата срещу желанието на компаниите, а в някои случаи и задължението им, да обучават и да изискват комуникация със специалисти, които правилно боравят със застрахователните термини и има по-задълбочени познания.

Управлението на този поток от взаимоотношенията изисква системно следене, ритмичност в провеждането на бизнес срещите и детайлна подготовка по отношение на посланието, което следва да се предаде - неговото съдържание, изработване, избор на канал и средство за реализация, всички те отговарящи на характеристиките на получателя.

Втора насока следва да е по отношение изследване на връзката спрямо другите застрахователни компании.

Въпреки, че акцент на изследването е връзката „застрахователна компания застрахователен посредник“, тя не следва да се разглежда изолирано от останалите участници на застрахователния пазар - конкурентите в лицето на другите застрахователни компании. Всеки тип застрахователен посредник по различен начин има възможност да взаимодейства със съществуващите застрахователни дружества. Тези връзки са регламентирани правно в Кодекса за застраховането.

Основните типове посредници са:

1) Посредник, предлагащ застрахователни услуги като допълваща дейност слаби връзки, най-често, с една компания, само за конкретни, малко на брой застрахователни продукти;

2) Застрахователен агент - силна връзка със само една компания по отношение на различни, но често не всички, продукти на компанията;

3) Застрахователен брокер - силна връзка с повече от една компания, а най-често и с всички компании на пазара, по отношение пълната гама от застрахователни продукти.

На фиг.3 нагледно са пренесени тези специфики в отношенията на застрахователната компания с различните видове посредници. От фигурата ясно личи, че следва да се предприемат различни стратегии по отношение на изследване, анализ и управление на всеки тип връзка.

Трета насока следва да е разглеждането на връзката в плоскостта на конкурентната структура на общозастрахователния пазар

Не трябва да се пренебрегва факта, че макар застрахователната компания да контактува с конкретния застрахователен посредник, тя всъщност контактува с всички негови клиенти. Последните от своя страна сформират сила, която определя конкурентната структура на пазара. Като техни представители застрахователните посредници акумулират сила, която променя позицията им спрямо застрахователната компания. Ако се модифицира моделът на Портър за изследване конкурентната структура на отрасъла, то той може да се представи като на фигура 4. 


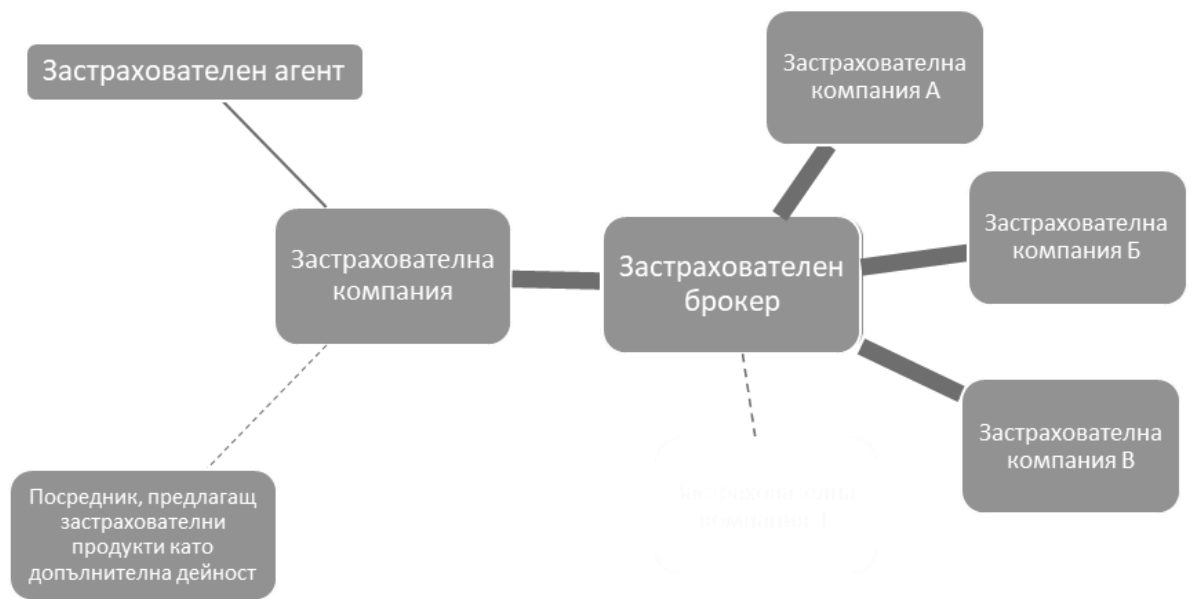

Фигура 3. Разлики във връзката на застрахователната компания с различните типове застрахователни посредници

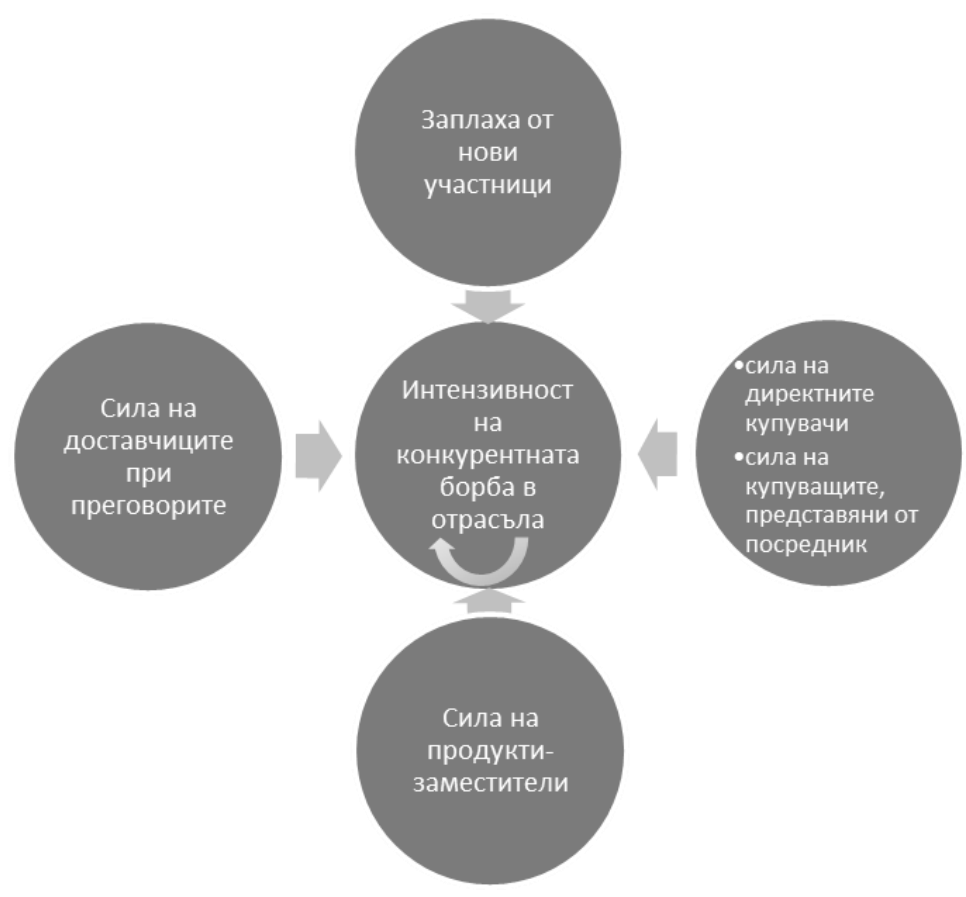

Фигура 4. Модифициран модел на Портьр за изследване на конкурентната структура на отрасъла

Това предполага възможността взаимодействието със застрахователните посредници да се изследва с предложените от Портър показатели за силата на купувачите. Съотнесени към застрахователните посредници тези показатели биха изглеждали така:

1) Брой на застрахователните посредници, действащи на застрахователния пазар;

2) Концентрация на застрахователните посредници, действащи на застрахователния пазар;

3) Относителен дял на реализирания премиен приход от застрахователни посредници на застрахователния пазар и към конкретната застрахователна компания;

4) Размер на комисионното възнаграждение;

5) Целесъобразност на закупуване на продуктите от различни застрахователни компании;

6) Равнище на стандартизация на застрахователните продукти, предлагани от посредника; 
7) Ниво на информираност на посредниците;

8) Доходи на купувачите;

9) Размер на разходите на посредниците за осъществяване на дейността си;

10) Разходи по прехвърляне към друг застраховател;

Изследването на тези допълнителни характеристики на връзката „застрахователна компания - застраховател посредник“ има много преимущества - широк обхват, разнопосочност, възможност за количествена оценка, разкриване на източниците на натиск, които посредниците могат да използват, но и очертаване на възможности за въздействие.

Този комплексен поглед на взаимовръзката с посредниците от три различни аспекта очертава в най-голяма пълнота сложната колаборация от възможности, желания, заплахи, силни и слаби страни на участниците в нея. Изграждането, поддържането, анализа и изготвянето на доклади за връзката „застрахователна компания - застрахователни посредници“ следва да се вмени като приоритетно задължение за звено „Брокерски бизнес“. Служителите в него следва да изготвят подробно и постоянно актуализиращо се досие, за предпочитане изцяло електронно, за всеки един посредник на застрахователното дружество. Системно да се обобщават данните от тези досиета в доклади (периодични или целеви), които да предоставя на мениджмънта за информация. Заедно с актюерските калкулации за развитие на риска, те следва да послужат за изграждането на стратегия и взимане на оперативни решения.

\section{Заключение}

Връзката „Застрахователна компания - застрахователни посредници“ е сложна и многопластова. На нея не следва да се гледа само от страна на генериран премиен приход. Нейното състояние и развитие предопределя конкурентната позиция на всяка застрахователна компания на общозастрахователния пазар. Съсредоточаването на мениджмънта на застрахователното дружество към създаване на стабилен и разнообразен застрахователен портфейл с балансиран рисков профил и експозиция, не следва да е в противовес с работата със застрахователните посредници. Дори напротив, идеята за изграждане на компания с рисково стабилна застрахователна съвкупност, заедно с постоянен, системен анализ на взаимовръзката с посредниците е предпоставката за успешно, дългосрочно и конкурентно позициониране на пазара.

\section{References}

1. Charles W. Curland (2004), Anatomy of the Insurance Broker: The Fundamentals for Extraordinary Success, Authorhouse

2. De Souza, Bernie, (2017), Getting "Yes" Decisions: What insurance agents and financial advisors can say to clients, Fortune Network Publishing

3. Dimitrova, V. (2017). Gross Margin and Buyer Power in Bulgarian Food Retailing, Economic Studies, Issue 6, pp.172-189

4. Draganov, Hr., Bliznakov, J, Dimitrova, G. (2001) Izsledvane na zastrahovatelniya Pazar v Balgariya, Sofia, UNSS

5. Kevin Glaser (2014), Inside the Insurance Industry, Right Side Creations, LLC; Revised edition

6. Kodeks za zastrahovaneto, v sila ot 01.01.2016 г., Obn. DV. br.102 от 29 Dekemvri $2015 \mathrm{~g}$

7. Misheva, I., (2016), Zastrahovatelen marketing, Sofia, Izdatelski kompleks - UNSS

8. Porter, M., (2010), Konkurentna strategiya, Sofia, Klasika i stil

9. Ronald L. Peters (1989), The Insurance Brokers' Handbook Hardcover, Random House Business Books

10. Salova, N., Danchev, D., Dimitrova, V., Traykov, H, Cvetkov, C., Grozdeva, D., (2015) Razvitie na targoviqta v Balgariya - sastoyanie, problem i predizvikatelstva. Varma: "Nauka i ikonomika"

11. Skipper, H., Kwon , W. (2007). Risk Management and Insurance : Perspectives in a Global Economy, Oxford : Blackwell Publ. 